\title{
Epilepsy and the Stigma Tag: A Personal Experience
}

\author{
Hope Muwanei Sikuka ${ }^{1}$, Dr. Ravi Paul M.D. ${ }^{2}$ Humphrey Chungu ${ }^{3}$ \\ ${ }^{1}$ Third Year Physiotherapy, Student, School Of Medicine, University Of Zambia. \\ ${ }^{2}$ Head, Department Of Psychiatry, School Of Medicine, University Of Zambia. \\ ${ }^{3}$ Msc. Clinical Neuropsychology, School Of Medicine, Department Of Psychiatry, University Of Zambia.
}

\begin{abstract}
Background: Epilepsy is common neurological condition in sub-Saharan Africa. It is traditionally linked to cultural beliefs and practices such as witchcraft. This manifest in stigma of those affected. Most patients live with the condition without proper medical intervention.

Aim:the article is aimed at sensitization using personal experience.

Method: A descriptive approach through past experience.

Conclusion: A need for collaborative approach to the intervention in problems of Epilepsy and the associated stigma.
\end{abstract}

\section{Introduction}

"Epilepsy refers to a recurrent paroxysmal disorder of cerebral function characterized by sudden, brief attacks of altered consciousness, motor activity, or sensory phenomena, and that convulsive seizures are the most common form of attacks but any recurrent seizure pattern is considered epilepsy,"(Taber's Cyclopedic Medical Dictionary, 1981). The condition of epilepsy is usually classified by the type of seizure the person has, and mostly in association to the area of the brain involved.

Epilepsy is the most common neurological disorder in the sub-Saharan Africa (Birbeck and Baskind, 2005). This implies that the condition of epilepsy does exist in most places within sub-Sahara of Africa. It is associated with increased morbidity, mortality and with much stigma. It is considered as a mental disorder in Zambia and many people still opt to seekthe services of witch doctors before they would finally see a health care practitioner (Ravi et'al, 2015). The implication of this is that there are a lot of myths and traditional beliefs which are associated with epilepsy.For instance, the belief that epilepsy is related to demonic possession or witch craft is so strong that peoplecontinue taking the treatment fromtraditional healers despite the fact that it is expensiveand the quality of this substances is unknown.

To make matters worse there are not many diagnostic facilities available in the country to diagnose epilepsy. This is coupled with a lack of trained health staff in treating the condition.As a result of this, patients continue to suffer with seizures throughout their life. In light of the above, this papergives an account of a patient and her struggle with epilepsy and both the associated beliefs and stigma related to the condition under the heading:

\section{My Experience As A Patient Living With Epilepsy}

"Based on what I was told, at birth I did not cry like all healthy babies do.They had to shake me, turn me upside down and even hit me a few times". My first seizure was when I was a month old andit was provoked by a high fever. My next seizure was at a year and four days old. I was misdiagnosedwith meningitis and the doctor suggested a lumbar puncture but the results came out negative.

Life was very hard for my familyduring my infancy because I was sick most of the time and had to be admitted in hospital frequently. Apart from them not having peace of mind, I assume I deprived my parents of quality sleep as I am told that I used to cry a lot at night. My parents were traumatized at the sight of seeing me seize in their arms and making them to worryabout me having another seizure.

My family strongly believed that it was witchcraft because according to them,the second seizure I had was when my mother went with me for my grandmother's funeral. I was only a year when the old lady died and my mother had to carry me along with her. The theory my family came up with was that, at the funeral someone must have used some kind of charm on me and I got sick. They said a relative who was jealous of my family, inflicted me with this illness in order to frustrate my parents. As it was in the past, even today people believe that a lot of strange things happen at funerals and because of thismy family believed that my case is a result of witch craft. Even though my parents would take me to the hospital once in a while and that I was put on anticonvulsants, they still continued to seek help of pastors for prayers as advocated by our family members. After some time, I stopped the anticonvulsants because they thought the drugs werenot making the situation better. They also took me to different witchdoctorssuggested by the people around us and these witchdoctors performed some rituals, but nothing seemed to help. I was introduced to traditional medicines which were expensive even 
though the medicine did not make a differenceto my condition. Worry became my parents' companion as I seemed not to get any better.

Even though I did not stop convulsing, I started going to school at the age of 4 years (1998). The seizures I was experiencing at this time were complex partial seizures. Unfortunately, by the middle of the year, I had to stop going to school because my seizures were severe and frequent such that I would convulse 10 to 15 times in one day. All this time I wasnot taking any conventional medicineapart from traditionalmedicine.

In August 1999, I was diagnosed with epilepsy at a Chinese clinic. It was then that I started taking some anticonvulsants, Anti-epilepsy Drugs (AEDs). I don't know the name of the drug I was taking because it was always written in Chinese and my parents never asked the Chinese doctor as to what it was. With the help of this medicine, my seizures reduced drastically and would happen once in a few weeks. My family was complacent with the fact that I was not seizing every day. I returned to school in grade 2 after two years, seeing that seizures werenot as frequent as previously, my parents gradually stopped my medicines. In grade 4, I had a seizure and I was taken back to the Chinese clinic. I was put back on the medication and again the seizures finally stopped in grade 6 .

From grade six (6), I remained seizure free till grade twelve (12)whilst I was intermittently on the anticonvulsant medications and it was on the $28^{\text {th }}$ of April, 2011, when I started convulsing again. This time I experienced ageneralized tonic-clonic seizure.Because of my birth history, some doctors thought it wasEpilepsy while others kept changing their statements. Others thought it was psychological (Psychogenic Non-Epileptic Seizures; PNES)which perhaps was caused by school and adolescence stress. I noticed that sometimes I would be blank and stare into thin air until someone taps me several times on the back. After this I would experience clonic seizuresinvolving the jerking of limbs.I experienced different types of seizures including simple partial and complex partial seizures. There was a time I was livingin a hostel facility near the school dispensaryand I was referred to the local General Hospital on several occasions because of recurrent seizure episodes. At the hospital, the doctors thought that I was having psychogenic seizures (PNES) so they suggested I go for counseling which did not help much. I had to stop schooling after term one, missed term two and only went back to school in term three in order to prepare for the examinations. During term two they referred me to The University Teaching Hospital (UTH) for a CT-Scan which reviewed no apparent abnormality. The problem became so bad that even, my mother had to come and live with me as the seizures would comeunawares.

It was so bad that during the examination period, I wrote two of my papers in Intensive Care Unit(ICU) at the General Hospital. At the hospital the doctors were getting panicky with my recurrent seizures. They were changing from one drug to another.

They wouldn't even leave time for observation.I was put on Phenobarbitone, Carbamazepine, Phenytoin and Gabapentin as well as combinations of two or three different drugs. The drugs were changed almost every two weeks or so.

Life was very hard at school. People shunned me away because they thought my condition was highly contagious. Sometimes when I fell in the walk way, Iam told that people especially my fellow pupils would scamper leaving me lying on the ground. People stopped talking to me or would avoid me and only a few of my friends supported me.The stigma was so much that I almost left school before I could finish writing my examinations. My family especially my father encouraged me to hold on a little longer until the exams ended. I felt so lonely and helpless. I felt like I was carrying the weight of the world alone on my shoulders. The Head teacher as well as other members of staffmade sure I sat at the back in the school hall during the examinations. I did not know the exact reason behind until one day when I asked the school head about it. In her responseshe told me: "you will disturb the other pupils". Another time before starting a paper, the Headmistress said to me, "Don't do what you like doing." I was so hurt that tears were running over my cheeksthroughout that examination.I thoughtlife was so meaningless to me and at that point, I felt very hopeless and helpless and all I did was to pray for death.

Thank God I passed my grade twelve examinations with 21 points, which is reasonably a good score.I applied in the School of Education for a programme of Bachelor of Education, in Special Education, at The University of Zambia (UNZA) and I was picked.I always wanted to do Medicine or do something health related, so I decided to rewrite my sciences and I ended up reducing the points from 21 to nine, because I got distinctions in the papers I rewrote. Without wasting any time, I wrote to the Vice Chancellor of UNZA for consideration to transfer to the School of Natural Sciences and thank God I was picked once again in the school of my wish.

During this all time, I observed the idea of taking anticonvulsants, going for psychological counseling and prayers. At some point, my parents suggested that we go see a traditional healer because a family friend said that we should specifically see one such healer who was very popular. This traditional healer supposedly cured his son of seizures and desperately, we had to travel to Sinda in the Eastern Province of Zambia in order to go and see him. We had some rituals done and we were told that once we reached home, they should do some 
African tattoos on me. I had to do this even though I never have or ever will believe in such things. Once we got home, I declined to have those African tattoos done on me to the dismay of my parents and family members.

Life at the University was noteasy either. I couldmiss classes most of the time because of recurrent seizures and studying was a bit challenging as well as preparing for tests. Before I went into University, at University Teaching Hospital, I was put on several drugs. When I went to a reputable private hospital, the clinician I was seeing decided to put me on Leveteracetam(Keppra).The clinician then requested an MRI which indicated no abnormal findings. This time I was having two to three seizures a week.

While in school, someone advised me to go and see an Epileptologist who then decided to discontinue the Leveteracetamand had to put me on Sodium Valproate. Seeing that the seizures weren't improving, the clinician then tried to increase the dose of the valproate but all this was to no avail. We moved from doctor to doctor, hospital to hospital, herbalist to herbalist and pastor to pastor but our efforts yielded no positive results. We lost all hope and now more than ever my family was convinced that witchcraft was involved.

I managed to qualify for Physiotherapy under School of Medicine, after writing my first year examinations under the School of Natural Sciences. Although things got a little better, school pressure made my condition worse. I continued praying to the Lord to help me find some answers to my problems, as things seemed to be becoming more and more difficult. I had even fully decided to continue going for psychological counseling, thinking thatit may help me to accept the situation. My relationship with my boyfriend also ended abruptly as he was ashamed of going out with me for fear of me convulsing in public and did not know how to handle me when I had an episode. This was so bad because I started feeling I was a burden to the people around me and my anxiety levels increased. Getting into another relationship after that was very difficult.

Sometime last year, I discovered that some family members went to buy some herbal medicines. In the beginning, I was dragged to see a witch doctor thatperformed a ritual and gave some herbal medicine to drink and performed some African tattoos on me. It is this same witch doctor who gave them that medicine. I tried my best to ask them not to take me there but they refused. I also tried to explain that these herbs may be dangerous if there were some drug interactions with the medicine I was taking but all to no avail. I even tried to explain beliefs as a Christian and that I don't believe in these kinds of things because God's time is the best, and that the Lord is the only true healer but all my words fell on deaf ears. Actually it was so bad that when I opposed this idea they threatened me that they will withdraw me from the University if I continued convulsing because the illness was affecting my studies, consequently affecting my health. I was so depressed because school for me is everything that makes up my being. Besides I could handle both my studies and the illness, so I saw no reason for me towithdraw. Just the thought of withdrawing broke my heart into a thousand pieces.

Generally, the current situation at the School of Medicine, on the reaction of people towards me has been good. People here have been more understanding of my situation and have been supporting and encouraging. Not many people label me as the girl who has seizures. My friends and my classmates have also been supportive and know how to handle the situation when I go into an attack although they still get into panic mood. However, things are still a bit difficult because people do come by telling me to go to different kinds of pastors and herbalists. The problem I have noticed with the herbalists and sometimes the pastors is that they persistently tell me to stop drinking the medicine especially after the prayers or having taken the herbs. The difficult part is that sometimes my parents want me to follow these instructions but the good news is that I always manage to get out of this and I donot stop taking the medicine. I also asked my parents to stop taking me to the witch doctors because it was affecting me greatly and fortunate enough they accepted. Besides, I also wanted them to come to accept the situation fully because I need all their support. My parents despite the great influence of culture, are well educated and they understand my situation but my concern is: "what of other patients who are not so lucky"? All I can say is that Epilepsy plays havoc to their lives.

It was until recently when a friend of mine suggested that I go and see a specialist in a tertiary hospital. The doctor who attended to me suggested that I discontinue the Valproate and I was put on Carbamazepine. The doctor told me and my family that I was never using an optimal dose of any of the medicines I was put on. Most anti-epileptics are given according to the body weight of the person and that the dosagehas to be increased to the maximum possible in relation to weight before adding another anti-epileptic or change to another drug. Then I realized that, this could have been the mistake most of the treating physicians were making as none of them had put me on an optimal dose of one anti-epileptic drug and were just trying combination of various drugs in low doses which interacted with each other and thereby reducing their efficacy to control seizures, and this consequently increased side effects that include cognitive impairment. Sometimes I was prescribed a medicine every other day whereas the half life of that drug was only 6 hours. This is when I understand the intricacies of anti-epileptic drug treatment and as I think back now I realize how wrongly I was managed in the past. This is typical of epilepsy management in the country where most patients continue to have seizures for their lifetime. They become happy with the fact that they have fewer seizures or the seizures are not as rigorous as before. The goal of epilepsy treatment is to make the person seizure free and not to have a compromise with fewer seizures or less severe episodes. 
The doctor gradually increased my dose of Carbamazepine to $1200 \mathrm{mg}$ per day which has immensely helped me in being seizure free. I did not seize for two months at a stretch which has never happened in the last seven years. The other good news is that I donot have any side effects from the medicine like I used to have earlier.

The Lord had finally answered my prayers because the seizures have reduced drastically and now I live a better life than before. Since I started taking the Carbamazepine, the period between the seizures is slowly widening.If at all I have a seizure I would know because either I missed the dose or I was too stressed from the school examinations or I did not sleep well. It is still a little difficult for my family and friends to accept the situation but we are all trying by the grace of God.

\section{Discussion}

As outlined above, it can be said that it is not all seizures that are epileptic. Because of lack of specialists in the country, most seizures even though are non-epileptic are diagnosed as epileptic. This brings problems in a way that,even if the patient is on medication, his or hersituation tends to worsen even when this problem can be solved by visiting a psychiatrist.

The diagnosis of the type of Epilepsy can be very important as some medicines are the drug of choice for one type of Epilepsy and can worsen another type. Carbamazepine is the drug of choice for Complex partial Seizures whereas it can worsen Absence Seizures. Therefore one has to be very cautious in deciding for the type of medicine to be used ${ }^{4}$. Other points of consideration are age, sex and socio-economic status of the patient. There are some medicines which have serious side effects in children or in the females. One such medicine is Sodium Valproate which can cause fulminant hepatitis if used in children below 10 years of age. Sodium Valproate can cause teratogenic side effects in the developing fetus if given to a pregnant female ${ }^{4}$. The treatment of Epilepsy has to be continued for several years and the patient has to take medicines every day. In lower income countries where very few medicines are available, the major focus is not on the drug of choice but on the continuity of the medicine used. If the medicine is expensive then the family will fail to afford it and will eventually stop the medicine leading to breakthrough seizures. Therefore it is preferable to be on medicines which are available free of cost in the local hospitals even though they are not the treatment of choice or have more side effects ${ }^{4}$.

In the differential diagnosis of Epilepsy, there are several psychiatric events which include panic attacks, conversion disorder, psychogenic non-epileptic seizures, dissociative states, hyperventilation syndrome, acute psychosis and malingering (DSM-IV-TR).

When clinicians carry out the necessary tests for diagnosis of epilepsy like EEG, CT-scan or an MRI and the result comes out negative, people believe that it is not epilepsy and begin to associate it with all sorts of myths. What people donot know is that investigations like EEG, CT-scan and MRI scan are not diagnostic of epilepsy. They are supportive of the diagnosis if a patient had an episode which could be a seizure. The best way to diagnose epilepsy is see the seizure episode itself. Therefore the patients family should be urged to video record any behavioural manifestations during an episode which will help the clinician to easily diagnose if it was a seizure or not. Moreover two- thirds of cases of epilepsy cases have an unknown cause while in others it may be inherited or may be caused by early life traumas or infections of the brain.

Treatments of Epilepsy include the use of several anticonvulsant drugs (Taber's Cyclopedic Medical Dictionary, 1981). One of the major problems noticed in the management of epilepsy is the sub-optimal use of anti-epileptic drugs. Most clinicians don't reach the recommended dose for the body weight. This under dosing will not help in controlling the seizures and the patient may become resistant to the prescribed drug. The patient's body weight should be regularly monitored and dose be increased and decreased proportionately and accordingly. Another issue is that Health professionals must take extra care when combining AEDs. This is because some AEDs may interact with one another and reduce or increase the efficacy of each other.

Also in combining drugs we may be increasing the side effects without causing any additional benefit to the patient. If any two drugs that cannot be combined are combined, the patient may get worse as they may reduce the efficacy of each other and the frequency of the seizures may increase. To help the patients control their seizures, the health workers must emphasize on taking the drugs on fixed time and not at any time they remember to take them. For females of child bearing age certain anti-epileptics are teratogenic and their use may be limited and other drugs may be preferred over them. Nevertheless if the patient is having uncontrolled seizures thenit is better to stay on the medication as the adverse effects of seizures are more detrimental to the patient than the side effects of the drugs prescribed.

\section{Conclusion}

All in all, Epilepsy like many other chronic conditions impacts the life of an individual in many ways hence people should work together to create awareness about the disease because stigma may continue to be a problem. In thiscurrent time, people still think that the illness is contagious hence discriminating against the 
people with this condition. A lot of people though epileptic are capable of doing wonders but are still scared to come out in the open due to stigma. People should also be encouraged to go to the hospital just as soon as the condition is identified in order to prevent adverse cognitive and behavioral consequencesresulting from improper handling of the condition.

The most important aim of this article was to let people know thatthatthere is still hope for people suffering from the condition of Epilepsy and that they can have better outcomes in life if they accept and look at this with a positive mind. Above all, it is time for everyone to stand up and together pursue the fight against stigma associated with epilepsy.

\section{Acknowledgements}

I give thanks to God Almighty for giving me the strength and courage to encourage others through my experience as a patient.

\section{References}

[1]. Taber's Cyclopedic Medical Dictionary, (1981)-F.A. Davis Company, U.S.A

[2]. Birbeck, G. and Baskind, R(2005). Epilepsy Care in Zambia: A Study of Traditional Healers. Lusaka.

[3]. Ravi Paul et al. (2015)Treatment seeking behavior of people with epilepsy at the University Teaching

[4]. and Chainama Hills Hospital.International Journal of Developmental Research, Vol. 5, Issue,11,

[5]. pp.6106-6111, November, 2015

[6]. Lishman Organic Psychiatry: A textbook of Neuropsychiatry. $4^{\text {th }}$ Edition pp 309-397. Wiley and

[7]. Blackwell, 2009. 